\title{
Performance of supercritical methanol in polyurethane degradation
}

\author{
Lu Liu, Lihua Tang, Zibin Zhu, Yanhui Ni and Yongqiang Wu \\ East China University of Science and Technology, Research Institute of Chemical Technology, Shanghai 200237
}

\begin{abstract}
Polyurethane is a group of block copolymer which is composed of diisocyanate, chain extender, and polyol, including polyurethane foam, polyurethane elastomer, waterborne polyurethane, etc. This research focused on thermoplastic polyurethane elastomer (TPU) which is formed with 4,4'-diphenylmethane diisocyanate(MDI), poly(1,4-butanediol-hexanedioic acid) diolpolyester(PBA) and extended with 1,4-butanediol(BDO). The degradation of TPU was carried out with the help of methanol as the supercritical solvent. The SEM of the reaction residues revealed the process of the depolymerisation. The products were measured by GC-MS and found out to be PBA, BDO and 4,4'-methylene diphenyl carbamate (MDC) which is the methylate of MDI. GC-FID, HPLC-UV and GPC were used to further analysis. The experimental results showed that supercritical methanol performed outstandingly in TPU recycling, it needed lower temperature and shorter time than regular methods. At $230^{\circ} \mathrm{C} / 70 \mathrm{~min}$, over $90 \%$ raw materials of TPU could be recovered .
\end{abstract}

\section{Introduction}

Polyurethane (PU) is composed of diisocyanate, polyether polyol or polyester polyol, and chain extender [1]. The property and utilization of PU could be manipulated by varying the raw materials. Consequently, it is one of the most promising polymers. Its products include rubber, fibre, resin, tackiness agent, coating material and functional polymer.

Recent chemical recycling methods of PU contain pyrolysis, hydrolysis, glycolysis [2-4], aminolysis, and hydrogenation et al. Among the above methods, glycolysis has more advantages in industrial applications because of the broad adaptability and mild reaction conditions. However, the glycolysis only recovers the polyol from $\mathrm{PU}$, and needs $2 \sim 5 \mathrm{~h}$ to complete the degradation reaction. The products are complicated and difficult to separate.

Supercritical methanol $\left(\mathrm{Tc}=239{ }^{\circ} \mathrm{C}, \mathrm{Pc}=8.1 \mathrm{MPa}\right)$ has moderate critical condition, weak hydrogen-bond interaction, and high dielectric constant. It performs excellently in polymer dissolving and extracting $[5,6]$. It's an important replacement of supercritical water in polymer recycling. Especially in the depolymerization of the condensation polymer (such as PET [7, 8], PC [9], PBT $[10,11])$, supercritical methanol not only plays the role of the solvent, but also participates in the scission of the polymer chain as the reactor. Besides excellent transmission characteristic and dissolution characteristic, it also has splendid reaction characteristic.

In this work, thermolysis was compared with supercritical methanolysis, in order to investigate the feasibility and effectivity of the later method, study of
TPU degradation behavior in sub-/supercritical methanol was carried out. By analysis and calculation, we found the maximum yield of MDC, PBA and BDO were $98 \%, 92 \%$ and $93 \%$, respectively. Consequently, the utilization of supercritical methanol in TPU degradation and recycle was efficient and promising.

\section{Experimental}

\subsection{Material and equipment}

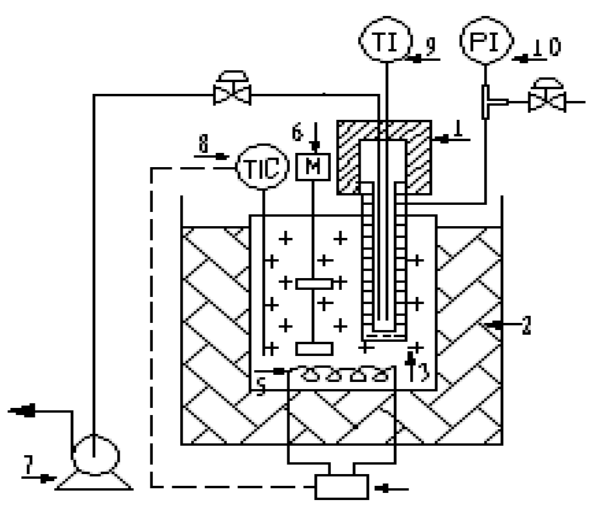

Figure 1. Schematic diagram of the experimental equipment 1.High pressure reactor 2.Insulating layer 3.Salt bath 4.Thermostat 5.Resistance wire

6.Stiring 7.Vacuum pump 8. Thermocouple

9.Temperature display instrument 10.Pressure transmitter

The polyurethane which was decomposed in this research was thermoplastic polyurethane elastomer (TPU): Bayer 
Desmopan ${ }^{\circledR} \quad$ CA205; The solvent was absolute methanol(AR,purity $\geq 99.5 \%$ ). The experimental apparatus is shown as Fig. 1, it was a high pressure batch reactor with a volume of $20 \mathrm{ml}$ made of $316 \mathrm{~L}$ stainless steel. The reactor was heated by molten salts which contained $50 \mathrm{wt} . \% \mathrm{KNO}_{3}$ and $50 \mathrm{wt} . \% \mathrm{NaNO}_{2}$. The volume of the part exposed to the air is less than $0.1 \mathrm{ml}$, so the affection of the unheated part to the whole system could be ignored. The temperature and pressure in the reactor were measured by pressure sensor and K-thermocouple, respectively.

\subsection{Experiment and characterization}

\subsubsection{The feasibility of TPU degradation in supercritical methanol}

$1.0000 \mathrm{~g} \pm 0.0002 \mathrm{~g}$ of raw TPU was weighed by electronic balance and fed into the above-mentioned high pressure batch reactor. The degradation condition was set as $250{ }^{\circ} \mathrm{C}$ 19.0MPa. The reactor was sealed up and vacuumized to $-0.01 \mathrm{Mpa}$ by water ring vacuum pump. $12.5 \mathrm{ml}$ of methanol(the mass ratio of raw TPU and methanol is $1: 10$ ) was extracted by needle tubing and inhaled by the negative pressure. Then the reactor was heated by the melting salt. After 20min, the reaction was finished, the reactor was taken out of the molten salt and put into cold water immediately. When the temperature of the reactor reduced to ambient temperature, the degradation products were taken out and analyzed by GC-MS(GC: Agilent 6890, MS: Agilent 5973N).

In addition, A WRT-3P TG was used in testing $30 \mathrm{mg}$ of TPU in the atmosphere of $\mathrm{N}_{2}$.

\subsubsection{Degradation of TPU in sub-/supercritical methanol}

The experimental procedure was the same as which was mentioned in 2.2.1. The degradation temperatures were in the range of $200 \sim 290^{\circ} \mathrm{C}$, the corresponding pressures were 3.0 13.0MPa. The duration of the degradation was $5 \mathrm{~min} \sim 70 \mathrm{~min}$ 。

Analytical instruments : Haixin GC-930, FID; Waters600 HPLC, Waters486 UV(246nm) ; JEOL JSM-6360LV scanning electron microscopy(SEM).

\subsubsection{Characterization of PBA in suitable degradation condition}

At $230{ }^{\circ} \mathrm{C} / 7.2 \mathrm{MPa}$, the degradation time was $5 \mathrm{~min} \sim$ 70min. After vacuum distillation, the products were dissolved in tetrahydrofuran(THF) and analyzed by GPC(PL-GPC50, mobile phase: THF).

\section{Results and discussion}

\subsection{The degradation results of supercritical methanol}

The degradation products in supercritical methanol $\left(250^{\circ} \mathrm{C}\right.$ 19.0MPa) were faint yellow liquid mixture. That indicated $20 \mathrm{~min}$ was enough for supercritical methanol to degrade TPU completely. By contrast, TPU decomposition started at $300^{\circ} \mathrm{C}$ and finished at $700^{\circ} \mathrm{C}$ in thermolysis, as shown in Fig. 2. Therefore, supercritical methanol was superior to thermolysis on account of lower decomposition temperature and higher efficiency.

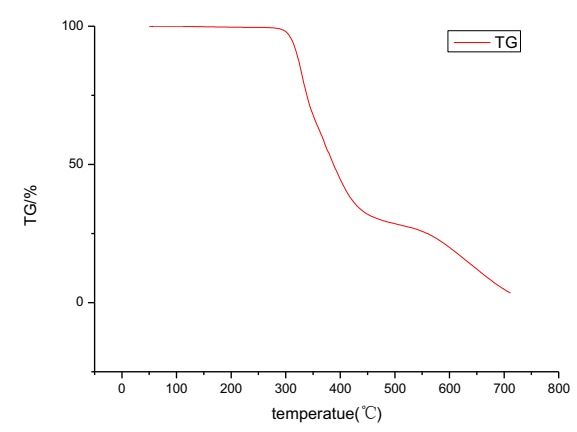

Figure 2. TG curve of TPU

Testing of the products mixture by GC/MS indicated that there were THF, BDO, dimethyl adipate (DMA), MDC, et al; Thereinto, THF was a byproduct from BDO cyclodehydration; A part of BDO was chain extender of TPU, the other was methanolysis product of PBA, as the same as BDO. GC was not proper to PBA which was a polymer itself. But from the methanolysis products of PBA, it could be inferred that the degradation products mixture also contained PBA.

\subsection{Degradation of TPU in sub-/supercritical methanol}

As the results shown above, the degradation products of TPU in supercritical methanol were MDC, BDO, PBA and its methanolysis products BDO, DMA. BDO and DMA were quantified by GC; MDC was quantified by HPLC [12]; PBA was measured by GPC. On the basis of these analyses, the influence of temperature and time on degradation rate and yields were obtained.

\subsubsection{Analysis on degradation residue}

The quality of the degradation residue was weighed and shown in Table 1 . At $200^{\circ} \mathrm{C} / 70 \mathrm{~min}$, the quality of the residue was $0.5076 \mathrm{~g}$. In the range of $200^{\circ} \mathrm{C}$ to $240^{\circ} \mathrm{C}$, the time of TPU decomposing completely was decreased significantly. When the temperature of the degradation was higher than $240{ }^{\circ} \mathrm{C}$, the degradation reaction completed within $10 \mathrm{~min}$.

The SEM images of degradation residues in $200^{\circ} \mathrm{C}$ to $250^{\circ} \mathrm{C}, 10 \mathrm{~min}$ were given as Fig. 3 to Fig. 9. There were plenty of micro areas on the surface of TPU, as shown in Fig. 3. Because TPU was a block copolymer consisting of hard segment and soft segment, hard segment was generated from MDI and chain extender, and could not be 
dissolved in soft segment which was composed of PBA. The alternative distribution of the two kinds of segments formed micro areas. This phenomenon was called microphase separation. In $200^{\circ} \mathrm{C} \sim 210^{\circ} \mathrm{C}$, the methanol molecule firstly infiltrated the amorphous soft segment. The polymer chains were decomposed to oligomers. As Fig. 4 Fig. 5 showed, the TPU fragments with microphase separation were observed. At $220{ }^{\circ} \mathrm{C}$, as shown in Fig. 6, the fragments continued to react with methanol, part of soft segment was dissolved in methanol, deprived from the polymer chains, the others twined around the hard segment. In Fig. 7 Fig. 8, the degradation temperature rising to $230^{\circ} \mathrm{C} \sim 240^{\circ} \mathrm{C}$, all the soft segments had removed from the TPU chains. Some of them attached to the hard segments which were spherical crystal arranged closely. At $250{ }^{\circ} \mathrm{C} / 10 \mathrm{~min}$, supercritical methanol diffused into TPU, and the soft segments were rapidly ruptured from TPU. The internal structure of hard segments rearranged and congregated into flake-shaped fragment, as shown in Fig. 9.

Table 1. Quality of the degradation residue

\begin{tabular}{|c|c|c|c|c|c|c|c|c|c|c|}
\hline \multirow{2}{*}{$\begin{array}{c}\text { Degradation } \\
\text { time/min }\end{array}$} & \multicolumn{9}{|c|}{ Quality of the degradation residue/g } \\
\cline { 2 - 14 } & $20{ }^{\circ} \mathrm{C}$ & $210^{\circ} \mathrm{C}$ & $220^{\circ} \mathrm{C}$ & $230^{\circ} \mathrm{C}$ & $240^{\circ} \mathrm{C}$ & $250^{\circ} \mathrm{C}$ & $260^{\circ} \mathrm{C}$ & $270^{\circ} \mathrm{C}$ & $280^{\circ} \mathrm{C}$ & $290^{\circ} \mathrm{C}$ \\
\hline 10 & 0.8084 & 0.7718 & 0.6043 & 0.3045 & 0.103 & 0.0173 & 0 & 0 & 0 & 0 \\
\hline 20 & 0.7777 & 0.6812 & 0.4678 & 0.23 & 0 & 0 & 0 & 0 & 0 & 0 \\
\hline 30 & 0.7323 & 0.5343 & 0.3291 & 0.1 & 0 & 0 & 0 & 0 & 0 & 0 \\
\hline 40 & 0.6372 & 0.5025 & 0.1962 & 0.05 & 0 & 0 & 0 & 0 & 0 & 0 \\
\hline 50 & 0.5769 & 0.3928 & 0.1433 & 0 & 0 & 0 & 0 & 0 & 0 & 0 \\
\hline 60 & 0.5934 & 0.28 & 0.0827 & 0 & 0 & 0 & 0 & 0 & 0 & 0 \\
\hline 70 & 0.5076 & 0.1514 & 0.0367 & 0 & 0 & 0 & 0 & 0 & 0 & 0 \\
\hline
\end{tabular}

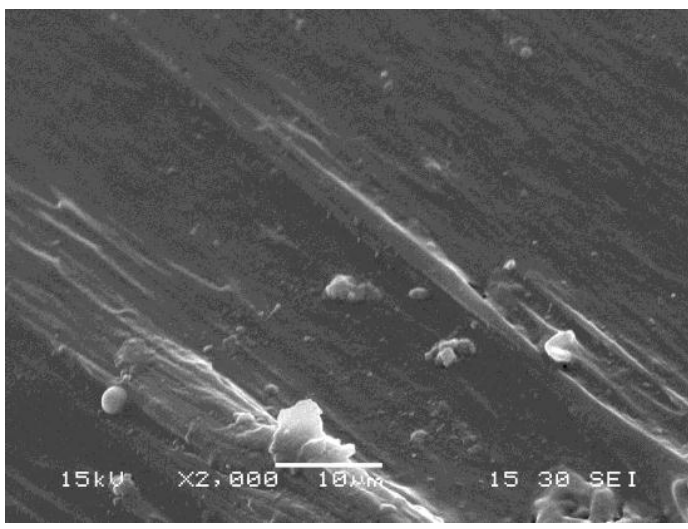

Figure 3. SEM image of TPU surface

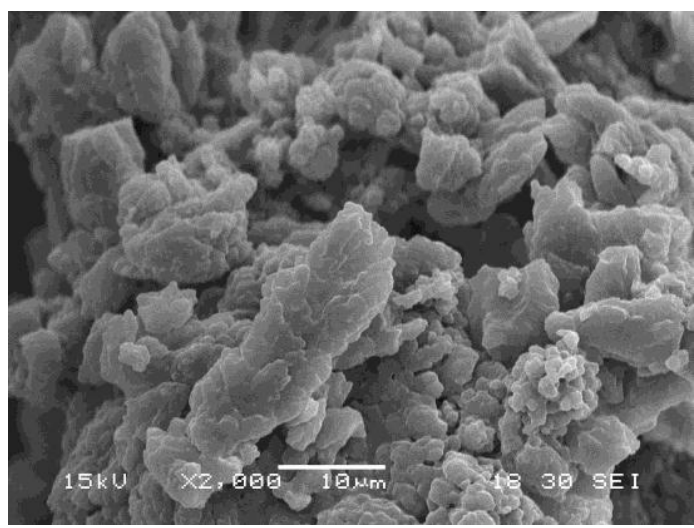

Figure 4. SEM image of the degradation residue at $200^{\circ} \mathrm{C}$ $/ 10 \mathrm{~min}$

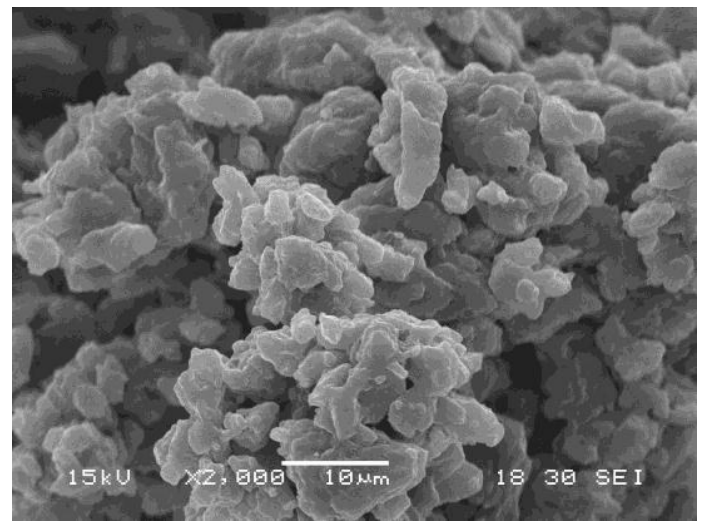

Figure 5. SEM image of the degradation residue at $210^{\circ} \mathrm{C}$ $/ 10 \mathrm{~min}$

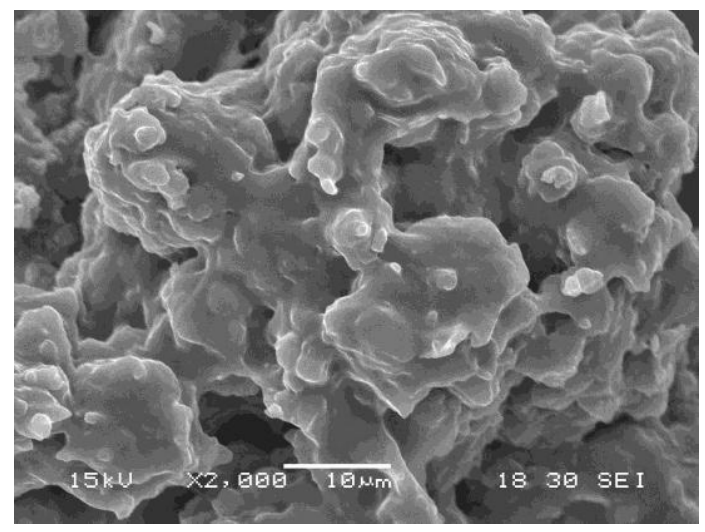

Figure 6. SEM image of the degradation residue at $220^{\circ} \mathrm{C}$

$/ 10 \mathrm{~min}$ 


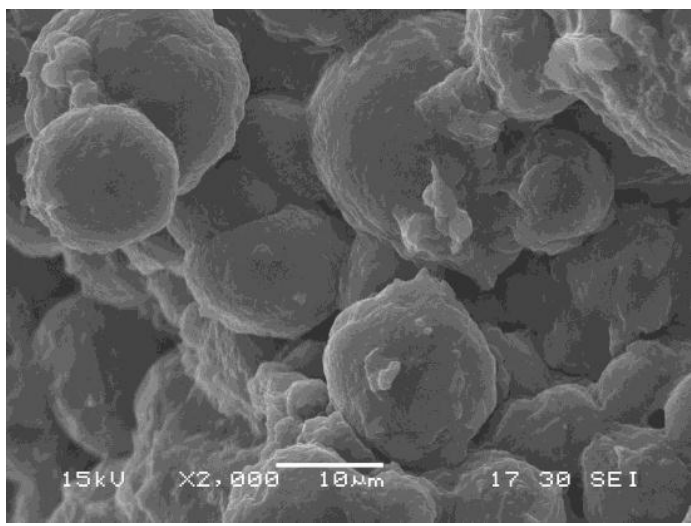

Figure 7. SEM image of the degradation residue at $230^{\circ} \mathrm{C}$ $/ 10 \mathrm{~min}$

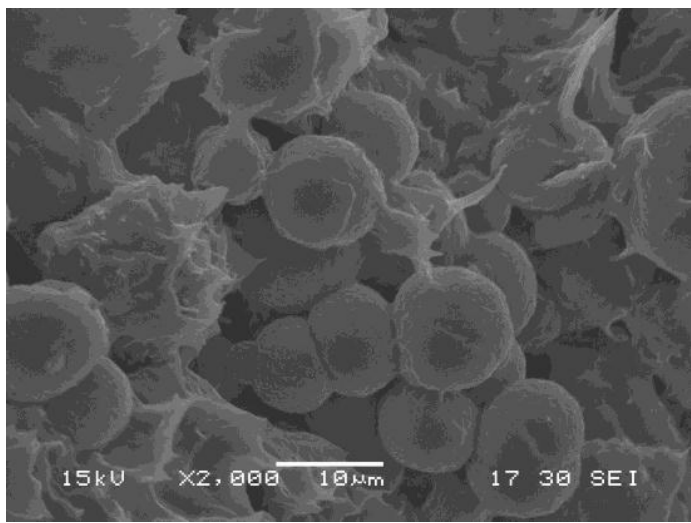

Figure 8. SEM image of the degradation residue at $240^{\circ} \mathrm{C}$ $/ 10 \mathrm{~min}$

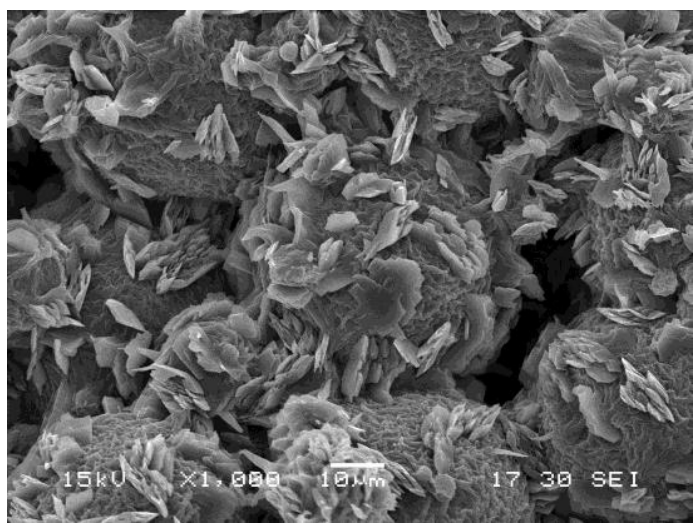

Figure 9. SEM image of the degradation residue at $250^{\circ} \mathrm{C}$ $/ 10 \mathrm{~min}$

\subsubsection{Analysis of the degradation products mixture}

During the main products of the depolymerization, BDO, DMA were measured by GC internal standard method with naphthalene as the internal standard substance. While MDC had high boiling points, and would decompose above $200{ }^{\circ} \mathrm{C}$. GC method was not appropriate.

To ensure the isocyanate $\left(\mathrm{NCO}^{--}\right)$reacting entirely, the products needed to be treated with excessive methanol before measuring by HPLC external standard method.

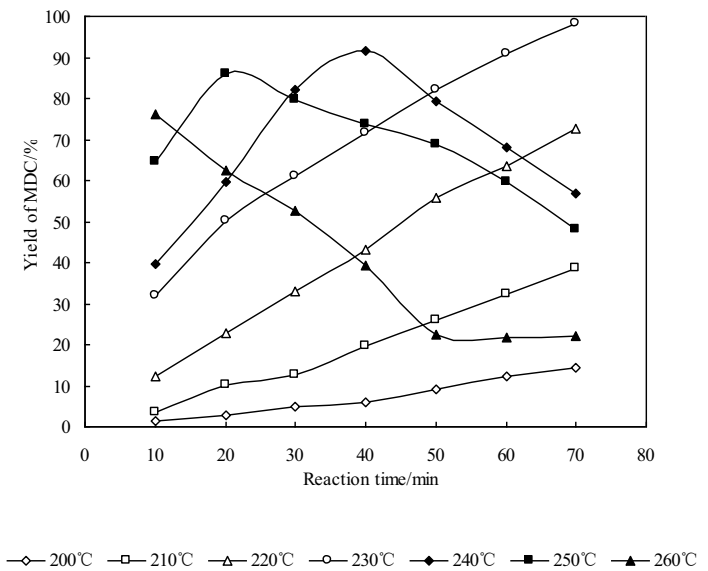

Figure 10. Relationship between yields of MDC and temperature

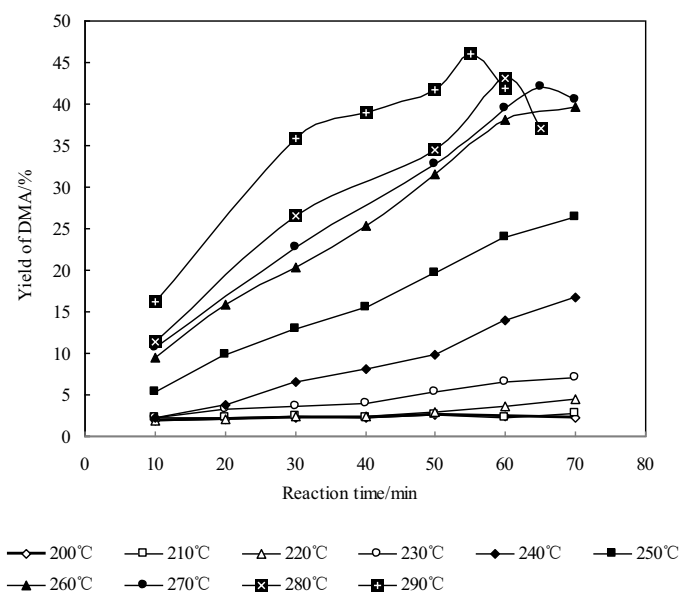

Figure 11. Relationship between yields of DMA and temperature

The influences of temperature and time on the main products MDC were represented in Fig. 10. In the temperature of $200 \sim 230^{\circ} \mathrm{C}$, the yield of MDC increased with the temperature. In $240 \sim 260^{\circ} \mathrm{C}$, the yield of MDC exhibited apparent peak values which showed earlier with increasing temperatures. On account of the secondary reaction above $250^{\circ} \mathrm{C}[12]$, the yield of MDC reduced sharply. The maximum yield of MDC reached $98 \%$ at $230^{\circ} \mathrm{C}$ 170min. Higher temperature was not good for MDC recycling.

DMA and part of BDO were decomposed from PBA. The yield of DMA was low(approximate $5 \%$ ) below $230^{\circ} \mathrm{C}$ 
as represented in Fig. 11. So that the PBA was rarely broken down below $230^{\circ} \mathrm{C}$. In addition, the yield of the chain extender BDO could reach to $93 \%$ (Fig. 12). To sum up, in subcritical methanol $\left(230{ }^{\circ} \mathrm{C} / 7.2 \mathrm{MPa}\right)$, the yields of MDC and BDO were high, and the decomposition rate of PBA was low.

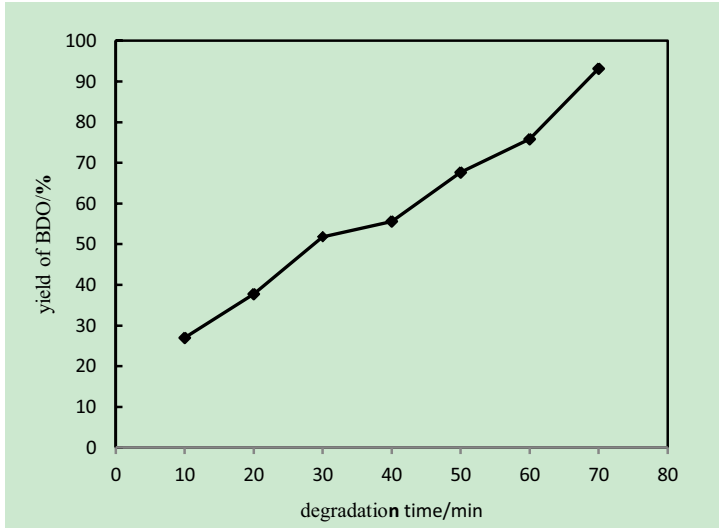

Figure 12. Relationship between yield of extender(BDO) and degradation time

\subsubsection{Characterization of PBA}

According to the study in 3.2 .1 and $3.2 .2,230^{\circ} \mathrm{C}$ /7.2 $\mathrm{MPa}$ was the appropriate condition of TPU degradation in methanol. But one of the main products PBA was polymer, it needed to be measured by GPC.

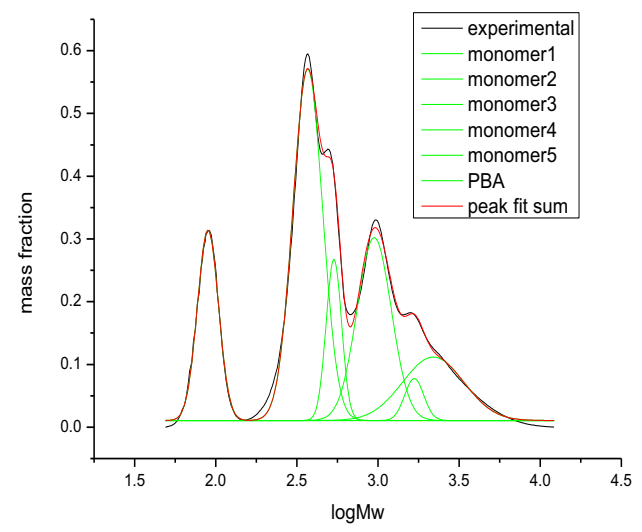

Figure 13. Molecular weight distribution of degradation products in $230^{\circ} \mathrm{C} / 20 \mathrm{~min}$

The molecular weight distributions (MWDs) of the products mixture at $230^{\circ} \mathrm{C}$ were analyzed by GPC. Take the MWD at 20min as an example, as represented in Fig. 13, the peak of PBA could be separated from the monomer peaks by origin8.5 PFM. The MWDs of PBA at different times were shown in Fig. 14. The molar concentrations of PBA were also obtained by calculation (Fig. 15). The maximum yield was $92 \%$.

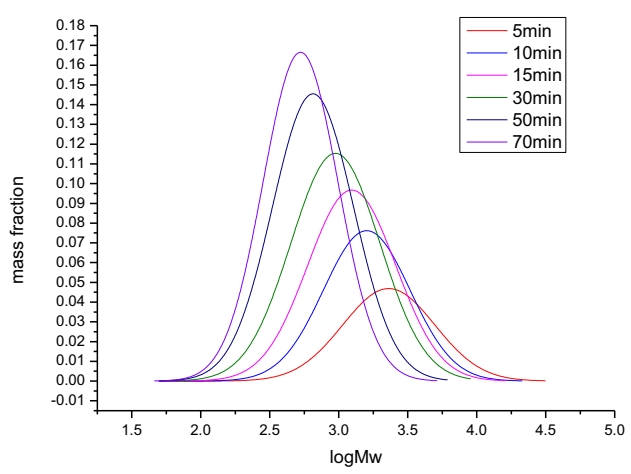

Figure 14. Relationship between MWD of PBA and degradation time

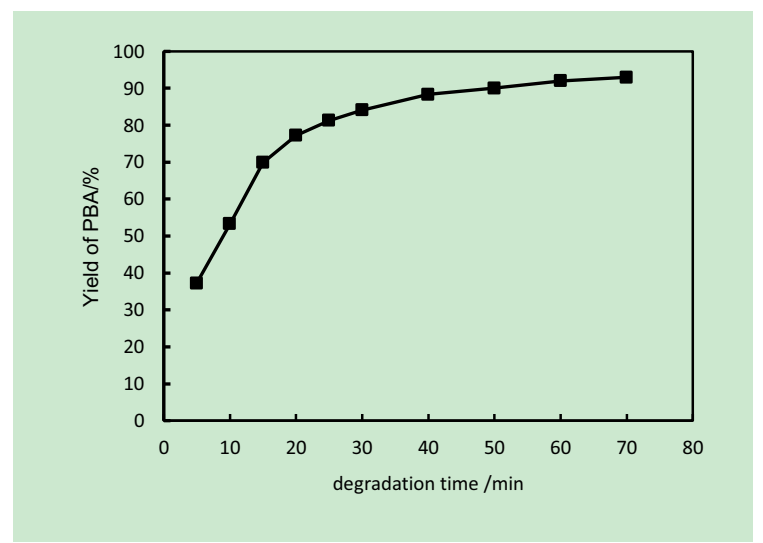

Figure 15. Relationship between yield of PBA and degradation time

\section{Conclusions}

Our research realized that supercritical methanol performed excellently in TPU degradation. TPU decomposed efficiently to obtain its raw material MDC, PBA and chain extender BDO. In the optimum degradation condition $230^{\circ} \mathrm{C} / 7.2 \mathrm{MPa}$, the yields of TPU MDC, PBA, BDO could reach 98\%, 92\% and $93 \%$, respectively。

\section{References}

1. Günter

Oertel.

Polyurethane

Handbook .Hanser .Publishers,(1985).

2. khalid mahmood zia, haq nawaz bhatti, ijaz ahmad bhatti. Methods for polyurethane and polyurethane composites, recycling and recovery: a review. React Funct Polym. 67, 675-6923(2007). 
3. chao-hsiung wu, ching-yuan chang, jiunn-kuen li. Glycolysis of rigid polyurethane from waste refrigerators. Polym Degrad Stabil. 75,413421(2002).

4. chao-hsiung wu, ching-yuan chang, chien-min cheng, hung-chang huang, glycolysis of waste flexible polyurethane foam. Polym Degrad Stabil. 80,103111(2003).

5. tsukahara $\mathrm{t}$, harada $\mathrm{m}$, tomiyasu $\mathrm{h}$, ikeda $\mathrm{y}, \mathrm{j}$ phy chem a, 112, 9657-9664(2008).

6. lalanne $\mathrm{p}$, andanson $\mathrm{j} \mathrm{m}$, soeten $\mathrm{j} \mathrm{c}$, et al. J Chem Phys A, 108,3902-3909(2004).

7. M. Goto, H. Koyamoto, A. Kodama, T. Hirose, S.Nagaoka, B.J. McCoy, Degradation kinetics of poly(ethylene terephthalate) in supercritical methanol, AIChE Journal.48,136-141(2002).

8. M. Genta, T. Iwaya, M. Sasaki, M. Goto, Supercritical methanol for polyethylene terephthalate depolymerization: observation using simulator. Waste Manage 27,1167-1177(2007).

9. Lei Chen. Depolymerization of Polyethylene terephthalate and Polycarbonate in Supercritical Methanol. Shang hai: East China University of Science and Technology(2003).

10. Huang Jie, Huang Ke, Qi Wenjie, Zhu Zibin. Process analysis of depolymerization polybutylene terephthalate in supercritical methanol. Polym Degrad Stabil 91, 2527-2531(2006).

11. Jie Huang, Junhe Yang, Minking K. Chyu, Qingming Wang, Zibin Zhu. Continuous-distribution kinetics for degradation of polybutylene terephthalate (PBT) in supercritical methanol. Polym Degrad Stabil 94: 2142-2148(2009).

12. Lu Liu, Lihua Tang, Yongqiang Wu, Yanhui Ni, Zibin Zhu, Degradation process investigation of thermoplastic polyurethane elastomer in supercritical methanol. Polym Degrad Stabil.98,2520-2528(2013). 